\title{
¿Un poliedro para pensar la infancia?
}

\section{Alberto Martínez Boom}

Jiménez Becerra, Absalón (2012). Emergencia de la infancia contemporánea. Bogotá: Editorial Universidad Distrital.

Recuerdo una entrevista a un escritor cubano, Antón Arrufat, para una cadena televisiva. En ella decía escuetamente que hablar de las cosas que ya sabemos raya en el mal gusto. Sería algo así como reiterar una cosa que se ha aprendido de memoria cuando precisamente lo que nos urge es intentar pensar de modo distinto. Ese otro hablar, ese otro pensar, constituye no solo una ética para el investigador sino también un esfuerzo en la escritura, en otras palabras, quebrar con la hipocresía de incurrir en elogios por simple compromiso moral o afectivo.

Quisiera entonces intentar un diálogo franco con el libro del profesor Absalón Jiménez desde diversos aspectos: su título, su periodización, su devenir explicativo, su causalidad histórica, su recorrido por el archivo y aquello que considero su mayor mérito: un dispositivo metodológico que mira a la infancia actual desde diversos planos de análisis, así: prácticas de crianza; preceptivas médicas y jurídicas; órdenes institucionales sobre lo escolar y lo familiar; derivas de la infancia en la ciudad y de los medios en la infancia, en fin, un paisaje múltiple al tiempo que imperceptible al sentido común.

Mucho se ha escrito sobre la infancia en la segunda mitad del siglo XX. Michelle Perrot recuerda en unos de los acápites de la Historia de la vida privada, investigación dirigida por Philippe Ariès y Georges Duby, que fue a propósito de la infancia que se promulgaron en Occidente las primeras leyes sociales'. Más allá de analizar su posible eficacia jurídica, importa resaltar este suceso como una inflexión que permitió pasar de prerrogativas liberales hacia la conformación de un derecho social. La infancia es vista desde esta perspectiva como una zona fronteriza donde lo público y lo privado se entrecruzan y chocan, a veces con violencia. Enfatiza Perrot que este forcejeo supuso también desarrollos de saberes médicos, psicológicos y normativos sobre la infancia cuyos efectos parecen contradictorios: "además de ser productores de control, lo son también de conocimientos gracias a los cuales la infancia se convierte en nosotros en un misterio insondable" (Ariès y Duby, 1991, p. 154). Dicho de manera clara, el interés por la 
infancia como algo social supone algo más que su pertenencia al nicho familiar, el infante adquiere un nuevo valor al recoger para sí una visión social del futuro: el ciudadano del mañana, el productor y el consumidor de un tiempo porvenir.

Los estudios sociológicos de Neil Postman tienen como tesis la manera como la tecnología transforma la sociedad, Postman (1996) afirma que "una nueva tecnología no añade ni quita nada. Lo cambia todo" (p. 31), es posible decir que el acceso indiferenciado a la información hecha por la televisión elimina los límites entre infancia y adultez, o mejor, "cuando la televisión hace público lo que antes era privado" (1994, p. 86) consolida una práctica que nos lleva a la desaparición de la infancia. Estos argumentos sobre el fin de la infancia, sobre la pérdida de la inocencia, y el horror frente a la emergencia de una infancia sexualizada en los medios, moviliza discursos que no son nuevos, la idea de la perdida de la inocencia ya estaba presente en Rousseau, lo que podríamos advertir con mayor detalle son los desplazamientos que aluden a fenómenos socialmente novedosos: familias plurales; mutaciones en las prácticas de autoridad en la familia, por ejemplo, la figura del padre amigo de sus hijos; la incapacidad para calcular las consecuencias de estos cambios en términos de compromiso o de carácter (aludo en esto al libro de Richard Sennett); la contundencia comunicativa e informativa de los medios, etc.

En Graciela Frigerio, la infancia no es pensada como instancia psíquica sino como una construcción innombrable, de ahí que componga los trazos de unas infancias, en plural, presentes en los discursos legales, institucionales y académicos, susceptibles de ser leídos, desde su sentido más antiguo y más amplio, como "la puesta topográfica de una técnica de consignación, constitución de una instancia y de un lugar de autoridad" (Frigerio, 2008, p. 10). Concuerdo con Graciela en que podemos llevar más allá la idea de multiplicidad, porque no es cuestión de decir simplemente: "hay muchas infancias", lo que interesa es mirar cómo está teniendo lugar esa reorganización discursiva de las infancias contemporáneas. En este sentido, la infancia vulnerable, la primera infancia, el trabajo infantil y otros nominativos cercanos no son realidades naturales que tienen una existencia objetiva por fuera de las instituciones que las regulan. Son el resultado de una construcción que se realiza en el cruce de dispositivos y relaciones enunciadas por la investigación, la ley y la opinión pública. 
En las elaboraciones de Mariano Narodowski la noción de infancia, siendo clave en la existencia de la pedagogía como discurso, está atravesada por una crisis de decadencia: "no se trata de una crisis de vacío o de vacancia, sino de una crisis donde la infancia moderna declina, pero reconvirtiéndose, esto es, fugando hacia dos grandes polos: la infancia hiperrealizada y la infancia desrealizada" (Narodowski, 1999, p. 47), la primera corresponde a la infancia de la realidad virtual, la segunda, alude a una infancia que se hace adulta en virtud a que debe sostenerse a sí misma. Destaco en este análisis la importancia de mostrar bajo qué formas se nos revela hoy el asunto de su porosidad y multiplicidad. Se insiste demasiado en presentarla como algo compacto, plenamente constituido, como una unidad coherente en los discursos sobre los derechos, sobre el consumo, sobre la educación y sobre su seguridad.

Muchas de las preguntas asociadas a la infancia, leídas por el profesor Jiménez dialogaron a su manera con estas perspectivas y encontraron en el manejo del archivo, vetas profusas de tramitación. Desde la literatura hasta el derecho, pasando por expedientes pediátricos, familiares, institucionales, policivos, psicológicos y educativos, las explicaciones ofrecidas por su investigación pintan un paisaje importante y útil para seguir investigando. La porosidad de las relaciones y la opacidad de las acciones muestran que para dar cuenta de esa rareza, que este libro nomina como infancia contemporánea, tuvo que avanzar en múltiples historiografías: de la planificación familiar, del juego y del juguete, del saber pediátrico, de la masificación del preescolar, del menor delincuente, del ICBF, del niño en la ciudad que educa, del menor trabajador y del televidente infantil.

Ninguna de las posiciones de diferenciación de la infancia es definitiva, la multiplicidad de circunstancias, de casos y de situaciones relativizan las posiciones aunque se conserva la precariedad de las infancias como condición permanente. La veta del historiador convencional, que transita tranquilamente de lo moderno a lo contemporáneo amparado en una periodización continua, causal y lineal resulta distante a las exigencias de un análisis que más que historiográfico es genealógico. El profesor Jiménez se propuso ese trayecto genealógico y al recorrerlo entretejió para sus lectores un poliedro de análisis que superaba con creces las posibilidades restrictivas de la interpretación enfocada a lo disciplinario, a lo social o a lo meramente institucional. Repetiría aquí la pregunta del filósofo: ¿cómo explicar el sentimiento de inseguridad generalizada en una sociedad que nunca estuvo tan protegida? (Lazzarato, 2006, p. 14). La emergencia de la infancia contemporánea es apenas el reflejo de una infancia dividida, jerarquizada y no- 
minada en sus desigualdades. De la gestión diferenciada de la infancia se desprenden miedos diferenciables que señalan, sin dudas, lo que podemos tolerar o soportar como cultura.

Destaco finalmente en este trabajo los riesgos propios de la formación doctoral, sus combates pero también sus solidaridades. Semejante esfuerzo supone valor, disciplina, rigor y, en el caso del profesor Jiménez habría que agregar, terquedad, sello distintivo de un camino que va hasta donde puede ir pero que no se cierra. No puedo menos que reconocer y congratularme con este libro, que a diferencia de la mayoría de trabajos sobre la infancia no habla de su objeto desde los cánones convencionales del agenciamiento internacional. Un trabajo serio, útil para la crítica, útil para la investigación.

\section{Referencias}

Aries, P. y Duby, G. (1991). Historia de la vida privada. Tomo 7. México: Taurus.

Frigerio, G. (2008). La división de las infancias. Buenos Aires: Del Estante.

Narodowski, M. (1999). Después de clase. Buenos Aires: Novedades Educativas.

Lazzarato, M. (2006). Políticas del acontecimiento. Buenos Aires: Tinta de Limón.

Postman, N. (1996). Tecnópolis. Barcelona: Galaxia Gutemberg.

Postman, N. (1994). The disappearance of childhood. Nueva York: Vintage Books. 